\title{
Digital Platforms: A New Grammar for Territories?
}

\author{
Stéphane Grumbach \\ (INRIA \& ENS Lyon, stephane.grumbach@ens-lyon.fr)
}

\section{Introduction}

The popularization of digital technologies has led to the emergence in recent years of a new category of players: digital platforms. Their inception constitutes a radical socio-economic transformation. In the span of one generation, the majority of the world's population has adopted the new digital services offered by technological companies, most of them born in the digital era, during the last two decades. Over the last years, the platforms they created have experienced unique growth in economic history, leading to the world largest corporations, both in terms of number of clients or users, as in terms of capital. Apple, Alphabet, Microsoft, Amazon, Tencent, Alibaba, Facebook have replaced crude oil corporations as the top ten market capitalizations ${ }^{1}$.

What is the ground of such a success, and what are its consequences? The revolutionary character of the platforms lies in the way in which they transform the activity of intermediation. Indeed, the new digital services they offer, although covering a wide variety of sectors of activity, have one essential point in common: they ensure intermediation with algorithmic means. Intermediation is an essential activity for the operation of any society. The role of intermediaries is to connect people with each other, or with the goods and services they need or which may be of interest to them. Far from being new, the activity of intermediation is ensured in all sectors, in various forms. At the individual level, resorting to care, obtaining a bank loan, arranging a trip, and more generally purchasing goods are all common activities that involve intermediaries: such as banks, shops, libraries, travel agencies, news organizations, postal services. On a broader scale, international trade, the exploitation of raw materials or the production of manufactured goods are all sectors based on a set of intermediation activities. Why digital platforms revolutionize intermediation? For a very simple reason. Indeed, it is basically an information processing operation. It is the information available to the intermediation operators which enables to identify the possible matches between producers and consumers of goods or services for instance. The operators therefore have to know at best the actors

${ }^{1}$ As of the third semester of 2017. 
involved, both producers and consumers. The quantity of knowledge in their possession and the quality of the analytical processing they are capable of are fundamental to implement a relevant and effective connection.

Algorithms and digital systems could have been used to improve or rationalise an existing activity, without affecting much the organisation of society. But things evolved on a rather different path. The deployment of digital technologies sets up a new social framework. It promotes the connection to the network of an increasing number of people as well as objects, devices and machines, and the gradual digitization of the real world in its dynamics. The expanding connection together with the rapid progression of computing power open new possibilities for the massive accumulation of data on human activities and its processing, which is now commonly referred to as "big data".

This transformation, as we will see, is radical in the sense that it leads to new objects, new classes, and new relationships between the objects. The framework in which we are used to think about the social and political organization is at stake. At the geopolitical level, the concept of nation-state with its associated sovereignty needs to be revisited with emerging complex dependencies leading to new power relationships. At the social level, the traditional division of labour and its organisation is shaken by new norms as well as new modes of interaction enforced by platforms.

Interestingly this global movement seems to be shaking the foundations of our organization, at all levels, while new constraints are emerging from our "natural environment", with natural ecosystems imposing tighter conditions on human activities, to say the least (Barnosky et al. 2012), rising great uncertainty on our capacity to adapt to these changes. Time to remember Marx's statement: "Mankind thus inevitably sets itself only such tasks as it is able to solve, since closer examination will always show that the problem itself arises only when the material conditions for its solution are already present or at least in the course of formation" (Marx 1859).

To a certain extent, platforms rely on the same material as modern governments: data. Statistics is the art of modelling the "things of states" with the appropriate mathematical tools, in order to influence them (Foucault 2007). So are social data, which feed statistics (Desrosieres 1999). Statistics allowed a new political rationality based on norms. They contributed to define normal life expectancy, unemployment rates, etc. and influence political action to guide behaviours towards these norms. During the last two centuries, the capacity of governments to obtain precise knowledge of their population has regularly been upgraded, with increasingly detailed censuses and technological improvements such as the digitization of census in the 1940's for instance. The raise of life quality and expectancy is a direct benefit of data collection and processing which support public health policies for instance.

This short paper aims at showing the mechanisms at play allowing the rise of actors that act on the real world by solely manipulating information. We then 
show that not only does it introduce new players, among the most powerful ones, not only does it condemn many actors of the old world to decay, but more importantly, it leads to a new socio-economic organisation with deep political and ethical consequences.

\section{The Rise of Pure Digital Actors}

History will remember that it is the platforms that first took advantage to such an extent of the potential of digital data through intermediation systems, which are all based on essentially the same architecture. They first use data that is produced outside the system: Web pages for the search engine, or personal data for social networks. By analysing and transforming these data, platforms are able to develop services. The use of these services by users in turn generates new data, traces of use, which in turn enables them to generate new services, including generic services, such as search engine trends, and personalized services, which exploit the fine knowledge that the platforms have of their users.

The accumulation of data thus allows platforms to offer new intermediation services, such as search engines or social media, unthinkable without digital technologies. These services enable intermediation to be carried out more effectively than by traditional actors. On the one hand, platforms have data that legacy actors do not have access to. On the other hand, these data and their exploitation allow platforms to offer a degree of personalization of service never reached before.

The success of platforms lies on their mastery of data technologies. But it would lead to miss fundamental aspects to reduce their success to technology. In addition to technological mastery, the platforms have succeeded in bringing about new economic models. It is important to understand that the operation of linking suppliers and consumers of goods or services is the basis of the economy of platforms. Economists speak of two-sided markets, that is to say markets associating two groups of actors whose activities are made possible by the network (Rochet-Tirole 2003). Unlike a traditional company that offers products or services, platforms produce essentially nothing. It does not mean though that ensuring the digital service is easy. The core of their added value is the facilitation of exchanges between users, companies, providing a common interface: the platform.

Platforms at first take existing data, essentially accessible to all. Somehow, they propose a new way to look at these data, and in fact suggest a new vision of the world, a new way to consider relationships and dependencies between objects, by considering the data. That leads to a new grammar, that is new rules to describe the relationships between objects. Interestingly, the Anthropocene (Crutzen 2006), that is the new geological era in which we live, 
has been promoted by a new way to look at the world, triggered by data, where the relationship between humans and nature is reconsidered (SteffenCrutzen-McNeill 2007). Platforms are transforming and taking control of the exchange of information between all actors, at the heart of the interdependencies of socio-economic systems together with natural ecosystems. They are the beating heart of the exchange of information of contemporary society at a global scale.

An interesting demonstration of the switchover of our economies towards platforms is given by the industry of mobile terminals, such as smartphones. Nokia and Blackberry that dominated the market, quickly lost their supremacy to the benefit of Apple and Android terminals, not because both are based on better technologies or more advanced features but because they rely on an open ecosystem, open to external developers who allow these tools to evolve continuously.

The economy of platforms depends on two markets simultaneously (ParkerVan Alstyne-Choudary 2016). Platforms indeed pursue two essential complementary objectives. On the one hand, they ensure a direct link with their basic users in order to be able to collect data on their activity. For platforms, the control of these data is central, it determines the quality of the services offered to the users. In addition, it allows them to monetize their audience with other companies. On the other hand, they seek to attract into their ecosystem, services offered by third-party actors. Openness to external applications is essential to offer a variety of services that meet the unbounded potential needs of users. In short, the challenge for the platforms is to develop both sides at the same time, and benefit from network effect.

A key factor in the power of platforms is precisely the "snowball effect" that can be triggered once the number of users increases. This growth tends to accelerate due to a phenomenon of increasing returns: the more users the platform has and the better it is able to offer them an improved service for the same price, which attracts new users, and so on in a positive feedback loop. This virtuous loop is simple to understand: the more users there are, the more data there is, the more relevant the intermediation system is. The more users there are, the more the platform attracts third-party services; The more thirdparty services and the more likely the platform is to attract users... This is the network effect.

This phenomenon of increasing returns is essential to understand the dizzying growth of certain platforms in recent years and the concentration, which is now the rule at the time of digital intermediation. Indeed, in almost all sectors of activity where digital platforms are involved, one platform dominates the sector, with a much higher number of users than its competitors.

Intermediation activities carried out by platforms spread across multiple sectors. In doing so, they challenge the position of traditional actors. Intermediation platforms profoundly change the economic organization 
because they have the capacity to "disintermediate" traditional actors, that is to say, to divest them of their connection with their "customers". The traditional territories bounding distinct activity sectors are progressively disappearing. This seriously shakes their business model, while in some cases it even eliminates their raison d'être. This ability to slip between users and service providers is due to two things. On the one hand, platforms are able to offer services that focus on consumer value rather than on the means by which it can be produced. In the transportation sector, for example, the service consists of a given trip at a given time, not the choice of a means of transportation such as train or plane. On the other hand, one of the essential properties of platforms is to bring consumers and suppliers up to the same level by offering new tools to the former: a personalized service allowing access to the offer that best suits everyone, together with recommendation option that allows users to express their level of appreciation, which translates into a new form of service quality certification by the user community.

\section{The Fall of Traditional Territories}

Traditional grounds of the economy are strongly disrupted, leading to new spaces, abolishing traditional borders (Atluri-Dietz-Henke 2017). The "disruptive" power of intermediation platforms on the rest of the economy invites us to revisit all sectors of activity from the angle of intermediation in order to identify the actors that could be impacted. All traditional services that interplay in one way or another between users and services will be affected by digital intermediation systems. Sectors as diverse as education, the press, health and taxation deserve special attention. They clearly establish a relationship between students and professors, journalists and readers, caregivers and patients, taxpayers and citizens. They are all to varying degrees affected by the irruption of the platforms.

Uber's well-known example shows that a platform can act as a direct intermediary between passengers and individual carriers, such as taxis, by abstaining from companies that manage fleets of vehicles. It should be noted though that Uber draws its strength from the very limits of the economic model of taxis. On the one hand, the quality of service of taxis is generally mediocre due to a phenomenon of organized rarity. On the other hand, the right to engage in taxi activity involves the acquisition of an expensive license-in Paris around $300 \mathrm{~K} €$, while in New York, it is around US\$ 1 million - which tends to burden the cost of service to the customer. With Uber, this cost disappears, which partly explains why taxi corporations are the first to be severely disrupted. 
It is at this level, the mastering of intermediation, that one of the deepest impact of the digital revolution will take place, with a very radical disruptive power, the one that will cause the greatest collapse of companies and more generally all sorts of players including public administrations, from the old world. It will affect in a similar way, territories, such as a metropolis or nations as well, simply by switching to a global platform activities, and in particular those that enforce behavioural norms formerly carried out by local actors.

Geography constitutes an interesting angle to consider digital activity. Platforms are remarkable for their ability to carry out intermediation between actors without having to be physically present on the territories where these actors are located. Platforms rely, of course, on physical infrastructures formed by data centres as well as communication systems, but these are not related to the "intermediated activity." Platforms intervention is based on the gathering of data from the territories. They have in general no direct interaction with the physical world in which the activity takes place, where the drivers work for instance, but they have a clear representation of the space, such as the cities (Calo-Rosenblat 2017), in real time with their flow of traffic and commercial exchanges among others.

In short, the disruptive impact of the platforms lies in the fact that they offer an intermediation disjoint from the production of goods or services of the physical world, and with a higher efficiency than that offered by traditional field intermediaries. It is in essence neither good nor bad, but it changes the rules of the game. Platforms are taking shares of territories and their socioeconomic control in a somehow orthogonal way. They redesign the sectors, and reconfigure the geography.

The other geographic specificity of the platform economy is that platforms exercise their global business from a handful of decision centres around the world. Few countries have given rise to large platforms, most of them are American and Chinese (Grumbach 2013). The concentration is even strong inside countries, with an accumulation in the San Francisco Bay Area for the US, and in three major places in China. Currently, platforms capture from some restricted geographic areas a remarkable part of the growth in the activity of local actors everywhere, not to mention the reduction in local taxation revenue that may result from this capture of activity combined with the, widely contested, tax optimization strategies of platforms (OECD 2015). The uneven distribution of the digital actors on the surface of the planet is striking. Most of them are concentrated in the USA, China, Russia, Japan, Korea, as well as some other Asian countries. No major platform has been developed on the European continent. In fact, neither the most popular devices and their hardware chips, nor the main popular softwares running them, such as operating systems, are developed in Europe, a situation which contrast with the technological capacity of the continent in traditional sectors. 
Catching up policies for territories without platforms might lead to very different strategies (Weber 2017), and rely on different ideological conceptions.

A first response to the concerns raised by the dominance of American platforms could be to give Europe the means to develop platforms able to challenge the US platforms used by European residents. This issue is crucial for two reasons. On the one hand, having large European actors would make it possible to ensure that a greater share of the value and jobs created by the economy of the platforms is anchored on European soil. On the other hand, the question of regulating the activity of platforms flying the European flag would arise in a very different setting as today, where regulations mostly apply to foreign corporations. This second point is essential because the stakes of regulation of the platforms go well beyond economic questions.

Territories need to deal with this shift of power. It must be noted that the rise of platforms is in many respects an irreversible mutation. The main reason is that they provide services of unsurpassed performance and depth, and potentially at a lower price than traditional services. The success of the platforms with the general public is first and foremost due to this quality factor. This point needs to be emphasized. Even if platforms today have a disruptive social impact they cannot be considered simply as yet another economic and social scourge. They could contribute to the best as well as the worse, but they have become a reality. The challenge is not to create dikes against the development of platforms, but to realize that they tend to upset the creation of value in the economy by proposing modalities of intermediation centred on the quality of service. The underlying principle relies on the strong believe that data should be harvested and used at its highest potential. In fact the "spirit" of the "digital" shares a lot with the spirit of the early capitalism (Weber 1904).

The relationships between the cyberspace and States has been controversial from the beginning, with a dominant libertarian vision in the early days, best illustrated with Barlow's declaration of independence (Barlow 1996). But since most of the digital industry has been developed after the 9.11 terror attack in 2001, issues related to national security and surveillance gave a peculiar historical twist to their development. State surveillance programs are making increasing use of platforms data, while this results in complex tradeoffs (Butler-Hidyegi 2015).

\section{The Shift of the Political Power}

The rise of platforms also induces a political revolution. The growth of platforms triggers key policy issues for at least two reasons. First of all, platforms are part of a process of horizontalization of society that takes place 
to the detriment of organizations operating in a vertical mode, such as the State. This logic of horizontality arises with the possibilities of connection and interaction that digital networks offer to individuals. Moreover, the activity of the platforms is deployed according to a mode of operation which differs radically from the large multinationals of goods or services in the traditional economic sectors. Indeed, the later penetrate the territories from the top, they must comply with a binding framework and, in case of conflict, negotiate with the authorities of the country. Conversely, platforms penetrate territories from the bottom, that is to say by directly reaching the citizens who adopt their services without restriction.

This mode of direct relation to local users allowed by remote intermediation has the consequence that the contradictions that may appear between the authorities and the platforms arise a posteriori once the platforms already have a significant presence on the territory and are adopted by a nonnegligible part of the population. In this context, it may appear somewhat politically risky, in any case complex for a territory to oppose the activities of platforms on its territory. The ban of Uber in London in the fall 2017 illustrates very well this situation (Topham 2017). Uber which claims that 3.5 million people have downloaded its app and used it at least once in the three months preceding the ban, got the support of 850,000 people signing a petition asking to revoke that decision.

The second element that has an eminently political resonance is that platforms are now taking over an ever increasing amount of data on human activities. Mastering the data means mastering information, and mastering information is a radical leverage of power. The data collected by the intermediation operators are incredibly rich. They enable their owners to develop a real-time knowledge of all the interactions between actors throughout the world. We are moving towards a paradoxical situation where platforms, although intervening at a distance, tend to accumulate information on the activities of population on territories that are more extensive than those available to local authorities (Faravelon-Grumbach 2016). Android or iOS have more geolocation sensors and data processing facilities than any administration to predict traffic for instance. Online sales platforms are able to produce economic statistics in real time. Alibaba does so for China. It is clear that the relative share of data produced by platforms increases to the detriment of that of public actors, whose data sources are both slow and costly.

The decline of the state supremacy in the control of information in its territory is growing. The management of very detailed maps of the territory, augmented with all sorts of data on activities, economic, transportation, etc. and including pictures constitute a good example of the rise of platforms in the knowledge of the activity of the territory of a temporal accuracy 
unmatched by governments (Siqueira-Leite-Beerli 2017). Their relative share of such data has thus declined continuously since the turn of the Millennium. New frontiers emerge on a different dimension than the geographic ones separating nation-states. Of course it would be imaginable to impose the geographic frontiers to the cyberspace, but it is neither what has happened not what can be envisioned for the future. The Balkanization of the Internet into partly independent systems difficult to reach from different territories seems hard to achieve (Daskal 2015). More interestingly, a different geometry is expanding, with new dimensions, allowing new power relationships between objects, in which battles of the future started take place, at all levels, economic supremacy, cultural influence, as well as military dominance.

The globalisation of the world economy, which resulted from the implementation of the principles of a liberal economy, facilitated the movement of people, goods and capital. It gave increasing facilities to private corporations to expand globally, while decreasing the power of governments to control them. Free movements of goods and capital constrained governments to adopt local rules that compete at a global scale. Such a competition progressively changed the political balance between concrete factual data and abstract political principles (Ostrom 2015). Numbers have acquired an increasing political legitimacy (Hansen-Porter 2017), at the same level as political principles, which lead various political scientists to speak about "governance by numbers" (Supiot 2015). Europe is again in a peculiar position since it depends widely on numbers produced by foreign agencies, much like it depends from foreign digital platforms (Verschraegen 2015).

The second trend, which is also calling for more data, is the desire to have more transparency and accountability of public action. Political systems of Western democracies, as well as other political systems, are under the pressure of public opinion for an increased efficiency and reliability in the political sphere. Pierre Rosanvallon speaks of "counter-democracy", that is new forms of democratic powers, taking shape "in the age of distrust" (Rosanvallon 2014). He distinguishes three counter democratic powers: oversight, prevention and judgment that strongly rely on a new "utopia" of transparency. Therefore, evaluating public policies, and making public administration data open to the citizens are new political trends that governments have to take into account (Collmann-Matei 2016). At the same time, the data of platforms is mostly inaccessible to third parties for reasons ranging from ethical to commercial.

In July 2013, while the UK was organizing the G8 meeting, a rather innovative open data charter was proposed and signed by all participants. Its ambition covers a large spectrum of simple objectives ranging from politics to economy, from better governance to increased development opportunities. The charter is really ambitious when it asserts the principle of opening all data by default, apart from essentially three categories of data that need protection related to 
national security, privacy, or intellectual property issues ${ }^{2}$. The charter has been followed by many decisions, at all level of governance, including directives of the European Commission, such as the directive on the re-use of public sector information.

If there is a sort of consensus on the benefits of data openness, the economic impact on the local economy is unclear, unless these data are not exclusively exploited by large foreign platforms? Open data could be more directly linked to support the emergence of platforms coming from the territory? For example, in China public authorities organize competitions to access the data. This allows them to retain control over the economic valuation of public data, and to better control the share of roles between public bodies and companies in order to manage cities for instance.

\section{Towards a Complex Biopolitical System}

This trends fragilises the legitimacy to act and to regulate that the public power historically held on its territory. Platforms might soon be able to offer services nowadays provided by public administrations, but in a much more effective way, merely because of their control of the data relating to the service and their ability to enlist local user communities in the management of the city for instance. This is suggested again by the example of Uber, whose capacity could go beyond the management of taxis to more global issues for the city. Similarly, the use of data is likely to play an increasing role in societal choices, particularly in a context where optimizing the use of resources will become an increasingly unavoidable environmental imperative. What better way, for example, than a platform to manage the electricity market by mediating large number of decentralized and unreliable producers and the mass of consumers?

One can wonder what platforms share with public services. In some ways platforms are very similar to public services. They provide services essential to the daily life of a large part of the population, as fundamental as energy supply, telecommunications or transport, for example. These services essentially respect the main principles of public service: continuity of service, equality in access and non-discrimination of users, as well as evolution and adaptability. Of course, a major difference between these new services and public services is the fact that they are deployed by platforms with an essentially commercial focus, and off the ground. This configuration will necessarily entail a redefinition of the respective rights and duties of public authorities and private enterprises.

${ }^{2}$ Text of the Charter available at https://opendatacharter.net/. 
It seems though that the normative power of platforms can only be strengthened in the future, to allow for more complexity resulting from more dependencies between socio-economic actors. As Laurence Lessig (2006) stated it very elegantly, code is law, the rules governing society will increasingly rely on algorithmic processes.

Of course, local communities still have certain means of pressure to negotiate with platforms the modalities of their activity on territories. Given that regulations are bound to local or national scale, the crucial issue at the level of a territory such as a metropolis, remains a pro-active economic policy to bring out real competitors on the local data and local connection with people. This is the key, as shown for example by the city of Seoul which blocked the arrival of Uber thus allowing a local competitor to emerge. There is probably little benefit in preventing the activity of a given platform, but ensuring a reasonable balance of power with platforms over a territory will be a topic of increasing importance.

How can this be achieved is not a simple question though. Some of the reasons of the inability of various countries to create local digital champions have been documented. In particular, the missing link with venture capital to meet the need of the accelerated growth of digital start-ups to avoid the classic alternative between failure or salvation by a US firm which buys the technology or the network of users if not both. There is also the question of the legislation relating to the digital economy, which takes complex contours at European level and might arguably hinder the deployment of European players throughout the continental market.

Most of the political and economic elites have not been trained to face the economic, social or political stakes of the digital economy as it unfolds in recent years. Various territories remain on backward battles, trying to preserve an untenable status quo for existing actors which, whether we like it or not, are destined to adapt or disappear, as well as rules, which are difficult to maintain in the digital era such as the right to be forgotten.

If Google and other platforms dominate some sectors today, many other markets remain to be explored, in health, education, energy, etc. If Europe does not take control of the intermediation that is being built in these sectors, it will lose the ability to anchor and share the economic value created in these markets, as well as may be more importantly, to contribute to define the new norms. Note that this question arises directly for the legacy companies that historically dominated their sectors: how to retain the primacy on the data related to the markets on which they intervene and how to make the exploitation of these data leverage their offer to meet the quality requirements imposed by the platform model? Very few corporations seem to address this issue with a real understanding of the consequences. General Electric (2016) is among the pioneers to massively invest in this translation in 
a new setting, with the development of an operating system for the industrial environment.

The confrontation between platforms and public administration is not balanced. Platforms have the capacity to raise billions and recruit intelligence at a global level, while States and local administrations are forced to cut their spending, at the expense of their ability to face these new issues, and rely mostly on large, locally recruited, aging staff. Local administrations capacity to apprehend markets, economic models and technologies in the digital economy remains limited. Another important gap between platforms and public authorities concerns the dependency from the regulatory framework. Where platforms sometimes deliberately free themselves from the rules in force because they are convinced that they will eventually evolve in their favour sooner or later, public organizations spend considerable energy verifying that their action is in the nails legally, which of course happens to the detriment of their agility. Clearly, if a metropolis intends to promote the development of a local ecosystem conducive to the emergence of the platforms of tomorrow, it is crucial for it to give itself the organizational, human and financial means to do so.

One can legitimately wonder why these changes happen so fast that the ruling class seems to be taken by surprise and unable to react appropriately. What is at stake is a completely different way of handling information, and the capacity to do so most often independently of the physical world. That is to say the capacity to act on the socio-economic system by only playing at the information level, from remote positions in space. Such a manipulation of information results in an increase of the interdependency between actors, accessing to an unlimited network of interactions. By doing so, part of the verticality of the social organisation collapses. The frontiers between territories, the division between sectors are weakened, while the intricacy of the dependencies increase.

These changes raise considerable political as well as ethical questions. Are they leading to a world which is better governed, and in whose benefit? Are the resources going to be more evenly shared or on the contrary are inequalities going to increase (O'Neil 2016)? Will the natural ecosystem continue to deteriorate? There has been a considerable interest for the protection of individuals, the traces of their activities, under the concept of privacy $^{3}$. But beyond the rights of individual, the new forms of dealing with information induce changes in the political organisation, with the emergence of new global powers and the disruption of established ones with new threats such as attacks on the information system itself, whose source might be hard to identify, and with consequences of unpredictable range.

${ }^{3}$ Many conferences among which the annual meeting on "Computers, Privacy and Data Protection" in Brussels. 
While the digital revolution occurs, the planetary conditions evolve towards a deteriorating environment for humanity, which will require profound changes in the political organisation, to facilitate the capacity to face collectively global challenges. States have shown their restricted ability to agree on common objectives and to implement them. They were not really designed for that purpose. Many of the means to act on the natural ecosystem require in fact to abolish existing barriers, to be able to take into account all interactions between seemingly independent sectors. This is particularly true for the preservation of the biosphere for instance. The capacity to govern from the information sphere could offer new means to balance production and consumption while taking into account all interdependencies with our planet. Platforms have demonstrated their potential for a better sharing of resources, although it is still unclear if their current influence on society triggers a better distribution of resources. But in any case, the adaptation of socio-economic systems to the new planetary boundaries (Rockström et al. 2009) will be done with and through digital platforms, and new modes of interactions (FoucaultDavidson-Burchell 2008), that make extensive use of information. Although the literature focuses mainly on the protection of individuals, the role of digital platforms in the transition of society towards sustainable politics is probably one of the most serious and complex ethical question of the digital era.

Acknowledgements: The author wish to thanks Patrick Degeorges for fruitful discussions.

\section{Literature}

Atluri, V., Dietz, M., \& Henke, N. 2017. Competing in a World of Sectors Without Borders. McKinsey Quarterly, July 2017.

Barlow, J. 1996. A Declaration of the Independence of Cyberspace. https://www.eff.org/fr/cyberspace-independence.

Barnosky, A. D. et al. 2012. Approaching a State Shift in Earth's Biosphere. Nature, 486 (7401), 52-58.

Butler, A. \& Hidyegi, F. 2015/2016. From Snowden to Schrems: How the Surveillance Debate Has Impacted US-EU Relations and the Future of International Data Protection. Seton Hall Journal of Diplomacy and International Relations, 17, 1/2, 55-80.

Calo, R. \& Rosenblat, A. 2017. The Taking Economy: Uber, Information, and Power. Columbia L. Rev., 6, 117.

Collmann, J. \& Matei, S. A. (eds) 2016. Ethical Reasoning in Big Data: An Exploratory Analysis. Berlin: Springer.

Crutzen, P. J. 2006. The "Anthropocene", in E. Ehlers \& T. Krafft (eds) Earth System Science in the Anthropocene. Berlin: Springer, 13-18. 
Daskal, J. 2015. The Un-territoriality of Data. Yale Law Journal, 125, 326-398.

Desrosieres, A. 1999. The Politics of Large Numbers: A History of Statistical Reasoning. Harvard: Harvard University Press.

Faravelon, A. \& Grumbach, S. 2016. Platforms as Governments. The Internet, Policy \& Politics Conferences.

Foucault, M. 2007. Security, Territory, Population. Berlin: Springer.

Foucault, M., Davidson, A. I., \& Burchell, G. 2008. The Birth of Biopolitics: Lectures at the Collège de France, 1978-1979. Berlin: Springer.

General Electric. 2016. The Industrial and Digital Worlds Are Converging, Not Colliding. GE reports 2016. http://www.gereports.com/industrial-anddigital-convergence-or-collision/.

Grumbach, S. 2013. The Stakes of Big Data in the IT industry: China as the next Global Challenger?. The $18^{\text {th }}$ International Euro-Asia Research Conference, The Globalisation of Asian Markets: Implications For Multinational Investors, 2013.

Hansen, H. K. \& Porter, T. 2017. What Do Big Data Do in Global Governance? Global Governance, 23 (1), 31-42.

Lessig, L. 2006. Code and Other Laws of Cyberspace. Available at codev2.cc.

Marx, K. 1859. A Contribution to the Critique of Political Economy.

O'Neil, C. 2016. Weapons of Math Destruction: How Big Data Increases Inequality and Threatens Democracy. New York: Crown.

OECD. 2015. Addressing the Tax Challenges of the Digital Economy, Action 1, Final Report. Paris: OECD Publishing.

Ostrom, E. 2015. Governing the Commons. Cambridge: Cambridge University Press.

Parker, G. G., Van Alstyne, M. W. \& Choudary, S. P. 2016. Platform Revolution: How Networked Markets Are Transforming the Economy - and How To Make Them Work For You. New York: Norton \& Company.

Rochet, J.-C. \& Tirole, J. 2003. Platform Competition in Two Sided Markets. Journal of the European Economic Association, 1 (4), 990.

Rockström, J. et al. 2009, Planetary Boundaries: Exploring the Safe Operating Space for Humanity. Ecology and Society, 14 (2).

Rosanvallon, P. 2014. Certain Turns of Modernity in Democratic Theory, in J.P. Gagnon (ed.) Democratic Theorists in Conversation. New York: Palgrave, 117-130.

Siqueira, I. R. de, Leite, C. C. \& Beerli, M. J. 2017. Powered and Disempowered by Numbers: Data Issues in Global Governance. Global Governance, 23 (1), 27-30.

Steffen, W., Crutzen, P. J. \& McNeill, J. R. 2007. The Anthropocene: Are Humans Now Overwhelming the Great Forces of Nature? AMBIO: A Journal of the Human Environment, 36(8), 614-621.

Supiot, A. 2015. La gouvernance par les nombres. Cours au Collège de France 2012-2014. Paris: Fayard. 
Topham, G. 2017. Uber Launches Appeal Against Loss of London Licence. The Guardian, 13

October 2017. https://www.theguardian.com/technology/2017/oct/13/uberappeal-london-licence-tfl.

Verschraegen, G. 2015. Fabricating Social Europe: From Neocorporatism to Governance by Numbers, in P. F. Kjaer \& E. Hartmann (eds) The Evolution of Intermediary Institutions in Europe. Berlin: Springer, 101119.

Weber, M. (1988, 190411). Die protestantische Ethik und der Geist des Kapitalismus, pp. 1-206. Tübingen: Mohr.

Weber, S. 2017. Data, Development, and Growth. Business and Politics, 19 (3), 397-423. 
Stéphane Grumbach
(INRIA \& ENS Lyon, stephane.grumbach@ens-lyon.fr)

Digital Platforms: A New Grammar for Territories?

\begin{abstract}
Digital platforms are reshaping the geometry of the world. Their wide adoption by the population worldwide for an increasing number of activities, confer them a dominant position, which challenges established powers. Their control over the global flow of data and their algorithmic treatment leads to new asymmetries of power. New systems emerge, that unlike the Westphalian States do not correspond to territories on a map, but to complex networks controlling sectors of activities at a global scale. It is a real challenge and a necessity to reinvent a grammar of territories, to be able to grasp the new objects and their dependencies, and address the related issues of social justice and sustainable interaction with our planet.
\end{abstract}

Keywords: digital platforms, algorithmic intermediation, information asymmetry, local government, division of labour, sovereignty, Anthropocene

Ethics in Progress (ISSN 2084-9257). Vol. 8 (2017). No. 1, Art. \# 7, pp. 101-116.

Creative Commons BY-SA 3.0

Doi: $10.14746 /$ eip.2017.1.7 